\title{
Considerações sobre a presença do esporte na educação física infantil: reflexões e experiências ${ }^{1}$
}

\section{On sports in physical education of childhood: reflections and experiences}

\author{
Ana Cristina Richter ${ }^{2}$ \\ Michelle Carreirão Gonçalves ${ }^{3}$ \\ Alexandre Fernandez $\mathrm{Vaz}^{4}$
}

\begin{abstract}
RESUMO
Considerando o debate acadêmico da área de Educação Física brasileira em torno do esporte como conteúdo de ensino, o presente trabalho reflete sobre a possibilidade de pensá-lo e experienciá-lo no contexto da Educação Infantil. Observando a cultura como elemento substancial da educação e o esporte como produção cultural, indaga pela responsabilidade dos professores na apresentação desse universo às crianças, na contramão das suas conformações competitivas, e a respeito do qual os pequenos não se encontram alheios. Com base nessas questões, apresenta experiências pedagógicas que tomam
\end{abstract}

${ }^{1} \mathrm{O}$ presente texto é resultado parcial do projeto Teoria Crítica, Racionalidades e Educação II, financiado pelo Conselho Nacional de Desenvolvimento Científico e Tecnológico (CNPq). Auxílio pesquisa, bolsas de produtividade em pesquisa, apoio técnico, doutorado, mestrado, iniciação científica e iniciação científica júnior).

${ }^{2}$ Doutoranda em Educação pela Universidade Federal do Paraná (UFPR); Bolsista Coordenação de Aperfeiçoamento de Pessoal de Nível Superior (Capes); Membro do Núcleo de Estudos e Pesquisas Educação e Sociedade Contemporânea da Universidade Federal de Santa Catarina (UFSC), Brasil.

${ }^{3}$ Doutoranda em Educação pela Universidade Federal de Santa Catarina (UFSC); Bolsista de Apoio Técnico do Conselho Nacional de Desenvolvimento Científico e Tecnológico (AT/CNPq); Membro do Núcleo de Estudos e Pesquisas Educação e Sociedade Contemporânea. Brasil.

${ }^{4}$ Doutor pela Universidade de Hannover, Professor dos Programas de Pós-graduação em Educação e Interdisciplinar em Ciências Humanas da Universidade Federal de Santa Catarina (UFSC); Coordenador do Núcleo de Estudos e Pesquisas Educação e Sociedade Contemporânea; Pesquisador do Conselho Nacional de Desenvolvimento Científico e Tecnológico( CNPq - Nível 2 - Ciências Humanas, Educação, Fundamentos da Educação), Brasil. 
práticas esportivas como conteúdo da Educação Infantil, entendendo que a Educação Física nesta etapa da Educação Básica também pode se ocupar dos grandes temas das práticas corporais, entre eles, o esporte, no sentido de criar, com os pequenos, outras formas de se relacionar com os objetos culturais. Palavras-chave: Educação Física; Educação Infantil; esporte; mediação pedagógica.

\section{ABSTRACT}

Sports as a schooling subject is a theme of extensive discussion in Physical Education in Brazil. In this context, this paper reflects on the possibility of its experience in Childhood Education. The paper puts in question the responsibility of teachers to show sport as cultural production to children, not as competition, but considering that culture is the substance of education and that children are not far from sports and culture. Two pedagogic experiences with sports to teach children are presented. This moment of basic education can be a time to learn important points of corporal practices, like sports among them, toward creating with children new forms to have a relation with cultural objects.

Keywords: Physical Education; Childhood Education; Sports; Pedagogical Mediation.

\section{Considerações iniciais}

O esporte como conteúdo escolar tem sido um dos temas mais presentes no debate acadêmico da Educação Física brasileira, em grande medida como objeto de crítica relacionada à influência da instituição esportiva sobre as práticas escolares. Elas seriam orientadas pela maximização do rendimento e pelo espírito competitivo, pela exclusão e pela submissão a regras universalizadas, pelos princípios da sobrepujança e das comparações objetivas, entre outros aspectos (BRACHT, 1999, 2009; KUNZ, 2009; TABORDA DE OLIVEIRA; OLIVEIRA; VAZ, 2008).

Nesta mesma dinâmica o esporte seria prática de maximização do capital corporal e vetor de representação de virilidade na conformação dos papéis de gênero. Ao contrário da ampliação do repertório de movimentos corporais, a prática de apenas algumas modalidades seria um limitante, muitas vezes associada à esperança ou fantasia de profissionalização. Em linhas gerais, esses elementos se encontram vinculados à crença no poder civilizador, regenerador e de inclusão social do esporte (BASSANI; TORRI; VAZ, 2003; TORRI; ALBINO; VAZ, 2007). 
Mas, por outro lado, o tema do esporte não deixa de ser revisitado e retomado como conteúdo da Educação Física escolar nos últimos anos sob diferentes perspectivas, favorecendo novas formas de pensá-lo e de experienciá-lo. Entre essas possibilidades, que não eximem a renovação de tensões na Educação Física, ganha relevo a perspectiva de ampliação do trato pedagógico com esse conteúdo, quando procurar-se-ia não apenas aperfeiçoar gestos técnicos ou reproduzir regras, mas, a problematização e a transformação desse conteúdo (KUNZ, 2009; ASSIS DE OLIVEIRA, 2005, entre outros). Para além da transmissão, trata-se também de privilegiar aspectos da produção, da transformação e da ressignificação das práticas esportivas, considerando o contexto em que elas se realizam, o que inclui uma ampla consideração da cultura como campo de possibilidades (TABORDA DE OLIVEIRA; OLIVEIRA; VAZ, 2008).

No tocante à Educação Infantil, o esporte geralmente não encontra lugar, já que, quando presente nos currículos das instituições, a Educação Física tem se legitimado principalmente pela via das práticas psicomotoras, pelo desenvolvimento de habilidades preparatórias para a alfabetização e pela recreação, como nos lembra Sayão (2004), ou, mais recentemente, pela severa crítica aos "padrões escolarizantes" que regem o ensino fundamental, considerando o entendimento de que a Educação Infantil atende crianças e não alunos e a necessidade de estruturação de uma prática pedagógica assentada nos direitos das crianças fundamentalmente orientada pelo trinômio brincadeira-interação-manifestação das múltiplas linguagens (dramática, musical, corporal etc.) infantis (ROCHA, 1999).

Quando não ignorada, a referência ou visibilidade do esporte aparece sobremaneira vinculada ao reforço ao direito das crianças ao movimento em espaços amplos. Isso acontece no contexto do incentivo à educação e ao cuidado dos pequenos a partir de práticas que envolvam o movimento e o conhecimento do mundo por meio da brincadeira, do jogo do faz de conta, da imitação, da apropriação da imagem corporal, do desenvolvimento da força, da agilidade e do equilíbrio físico. Exemplar é o que salienta Campos (2009, p. 14) nos Critérios para um atendimento em creches que respeite os direitos fundamentais das crianças, documento publicado pelo Ministério da Educação (MEC), onde se lê que "nossos meninos e meninas tem oportunidade de jogar bola, inclusive futebol.". Já nos Referenciais Curriculares Nacionais para a Educação Infantil (RCNEI), também divulgado pelo MEC, podemos observar orientações didáticas que fazem referência ao repertório de práticas presentes no meio em que as crianças vivem, sendo que "uma criança criada num bairro onde o futebol é uma prática comum, poderá interessar-se pelo esporte e aprender a jogar desde cedo." (BRASIL, 1998, p. 24). Nesse sentido, destaca-se que "é grande o volume de jogos e brincadeiras encontradas nas diversas culturas que envolvem 
complexas sequências motoras para serem reproduzidas, propiciando conquistas no plano da coordenação e precisão do movimento." (BRASIL, 1998, p. 24). O documento sugere ainda, a "participação de meninos e meninas igualmente em brincadeiras de futebol, casinha, pular corda etc.” (BRASIL, 1998, p. 37. grifo nosso).

Neste sentido, encontramos em Cavaralo e Muller (2009) importância conferida ao trabalho com o eixo "movimento" nas instituições de atendimento à pequena infância, destacando os objetivos gerais presentes no Referencial Curricular Nacional para Educação Infantil no que se refere à descoberta e ao conhecimento do corpo pela criança, à valorização de hábitos de cuidado com a própria saúde e bem-estar, à brincadeira e à utilização de diferentes linguagens com vistas ao enriquecimento de sua capacidade criativa. As Autoras também assinalam que a Educação Física se faz presente no Estatuto da Criança e do Adolescente, relacionando-a com o "direito à liberdade", que abrangeria a brincadeira, a prática de esportes e a diversão, conjunto que não deve ser negligenciado na educação de crianças pequenas.

Em suma, podemos observar certo distanciamento da Educação Infantil das frequentes discussões da área de Educação Física em torno do esporte, além de escassa referência a ele nos documentos que tratam do ensino para os pequenos, o que gera uma ausência de tematização das modalidades esportivas nos currículos de Educação Infantil. Nos RCNEI, por exemplo, ele aparece discretamente delimitado pelo eixo denominado "movimento" que, na conjuntura desse documento, abrange conteúdos vinculados a "expressividade" e "equilíbrio e coordenação".

Para além dessas orientações, é preciso lembrar que o esporte é um fenômeno de imensa e intensa abrangência em nossa sociedade e os ambientes educacionais não se encontram alheios a ele. Mesmo que não seja ministrado como conteúdo, observa-se sua presença entre as crianças porque há outros espaços e tempos, instituições e instâncias culturais que, embora não tenham a intenção explícita de ensinar, "transmitem uma variedade de formas de conhecimento que embora não sejam reconhecidas como tais são vitais na formação da identidade e subjetividade" (SILVA, 2007, p. 140). Este é o caso do sistema esportivo, representado, por exemplo, por sua enorme presença nos meios de comunicação de massa e no caráter mobilizador que certas modalidades apresentam, em especial no Brasil, o futebol. Isso considerado, e também que as instituições de Educação Infantil são ambientes educacionais que cada vez mais contam com a presença de professores de Educação Física, que o esporte é uma produção humana e a cultura é elemento substancial da educação, não deveríamos então perguntar pela possibilidade da presença do esporte nos currículos e propostas pedagógicas das instituições que atendem a pequena infância? E 
desse modo, refletir também a respeito das conformações a partir das quais as crianças estabelecem contato com esse conteúdo cultural e, então, pelas formas de abordá-lo no interior das instituições?

As perguntas acima pontuadas, bem como as demais questões inicialmente expostas nesse trabalho, colocam-nos a exigência ou pelo menos a possibilidade de problematizar: a) as pedagogias do esporte presentes em nossa sociedade (na mídia, nos estádios, nas quadras e nas escolinhas de esporte, por exemplo) e que educam os sentidos e as condutas, ao lado da ausência ou da pseudovalorização no trato pedagógico do esporte nos ambientes educacionais de atendimento à pequena infância; b) a educação (e o cuidado) infantil pautada nos direitos das crianças, sobretudo no que se refere à brincadeira, de um lado e, de outro, ao conhecimento produzido pela humanidade ou, noutros termos, na cultura como substância da educação; c) a visão do professor de Educação Infantil como ser de bastidores, organizador dos espaços onde as crianças agem "livremente" em concorrência com a possibilidade de atuarem como representantes do mundo, aproximando os pequenos dos elementos da cultura, mas também discutindo e operando com pressupostos teórico-práticos relativos à organização didática de conteúdos da Educação (Física), nesse caso, os esportes.

Nas próximas páginas, tratamos dessas questões tendo em mente a relação educação e sociedade e as possibilidades de mediação pedagógica com o esporte. Na sequência, buscamos apresentar algumas possibilidades de concretização do trabalho pedagógico, por meio de dois relatos que tomam o esporte como tema a ser abordado no âmbito da Educação Física da Educação Infantil. Finalizamos o texto realçando a Educação Infantil como espaço e tempo de promoção de experiências pedagógicas intencionais que podem favorecer formas de relação e aproximação das crianças com as produções culturais da humanidade - nesse caso, o esporte -, para além das suas conformações competitivas e a respeito das quais as crianças não se encontram alheias.

\section{Educação, infância, sociedade: esporte e mediação pedagógica}

Os debates em torno da institucionalização da infância nas últimas décadas, sobretudo aqueles vinculados à Sociologia da Infância, têm se colocado na contramão de programas e propostas vinculadas a práticas asilares, assistencialistas, filantrópicas, disciplinares e organizadas a partir de "princípios escolarizantes", a exemplo de áreas disciplinares e práticas subordinadas ao ensino fundamental. Diante desse quadro, a forma de ver as crianças se modifica, sendo que 
[...] atualmente emerge uma nova concepção de criança como criadora, capaz de estabelecer múltiplas relações, sujeito de direitos, um ser sócio-histórico, produtor de cultura e nela inserido. Na construção dessa concepção, as novas descobertas sobre a criança, trazidas por estudos realizados nas universidades e nos centros de pesquisa do Brasil e de outros países, tiveram um papel fundamental. Essa visão contribuiu para que fosse definida, também, uma nova função para as ações desenvolvidas com as crianças, envolvendo dois aspectos indissociáveis: educar e cuidar. Tendo esta função, o trabalho pedagógico visa atender às necessidades determinadas pela especificidade da faixa etária, superando a visão adultocêntrica em que a criança é concebida apenas como um vir a ser e, portanto, necessita ser "preparada para" (BRASIL, 2006, p. 8).

Nessa perspectiva, enfatiza-se a atenção às necessidades e aos interesses das crianças, visando

construir o ambiente físico destinado à Educação Infantil, promotor de aventuras, descobertas, criatividade, desafios, aprendizagem e que facilite a interação [...]. Acredita-se [...] que o professor tem papel importante como organizador dos espaços onde ocorre o processo educacional. Tal trabalho baseia-se na escuta, no diálogo e na observação das necessidades e dos interesses expressos pelas crianças, transformando-se em objetivos pedagógicos (BRASIL, 2006, p. 8. grifo nosso).

Se, de um lado, os estudos, as pesquisas, a legislação e os documentos que regem a Educação Infantil têm contribuído para repensar a infância e sua educação por meio da visibilidade reconhecida aos pequenos e tomando em conta sua radicação histórico-social e, talvez, portanto, escapando do poder disciplinar, tal como destaca César (2008), por outro, parece-nos que a ideia de autonomia da infância e dos professores como "organizadores dos espaços", como alguém que observa os interesses e necessidades das crianças para então elaborar uma ação pedagógica, tem também inadvertidamente contribuído para alguma confusão no que concerne ao papel do professor nesse ambiente, podendo fomentar práticas espontaneístas que eliminam o direito das crianças ao conhecimento produzido e a produzir, ou, mais especificamente no contexto da Educação Física, ao acesso às produções culturais que materializam a história das práticas corporais, entre as quais, mas não exclusivamente, o esporte. 
$\mathrm{O}$ acesso ao conhecimento historicamente produzido e culturalmente desenvolvido ocorre na relação entre adultos e crianças, o que, nos termos propostos por Benjamin (2002, p. 87), diríamos tratar-se, em síntese, da seguinte premissa: "se as crianças devem tornar-se um dia sujeitos completos, então não se deve esconder delas nada que seja humano.". Nesse sentido, o autor destaca a fatuidade da relação que a criança estabelece com o adulto e com os objetos e materiais que contam a história, ou de outro modo, a relação que permite a “constituição do Eu a partir do não-Eu" (ADORNO, 2000) e que implica na mediação dos adultos com as crianças, uma vez que a individualidade não é algo dado, mas decorre de vinculações com o mundo externo, da falta ou do desejo $^{5}$, do reconhecimento do semelhante no dessemelhante (o Outro, diferente), favorecendo a construção de novas significações e, assim, ampliando e ressignificando os limites da própria identidade.

Se considerarmos que parte das atuais reflexões a respeito da educação da pequena infância enfatiza talvez de forma exagerada o papel das professoras na organização do espaço pedagógico e que seu trabalho deve ser norteado pelos interesses expressos pelas crianças, corremos o risco de contribuir para que estas sejam mantidas artificialmente em seu próprio mundo, onde permanecem refugiadas no isolamento de si mesmas, como lembra Arendt (2002), e centradas na satisfação de interesses e necessidades vitais imediatas, sem qualquer relação com a permanência e a durabilidade, bem como com a renovação de um mundo comum materializado na cultura.

Os professores se colocam como representantes do mundo e têm o ofício de mediadores entre o velho e o novo, apresentando o mundo às crianças: um mundo que jamais permanece tal qual é, pois se renova continuamente por meio do nascimento, da vinda de novos seres humanos (Arendt, 2002) - e por que não dizer, de uma nova forma de relação com a própria cultura (inclusive a esportiva). No que lhe cabe, a Educação Física pode, então,

oportunizar o diálogo por meio do encontro das diversas culturas, proporcionando aproximação, experimentação, análise crítica e valorização das variadas formas de produção e expressão corporal

${ }^{5}$ Adorno (2000) também chama atenção para o elemento involuntário que acompanha a realização objetiva de experiências, e que se diferencia daquelas que adquirimos por meio de um processo ordenado. Exemplificando a questão, o autor faz uma referência à música: "experiências musicais na primeira infância a gente tem, por exemplo, quando, levado para deitar a cama para dormir, acompanhamos desobedientes e com os ouvidos atentos a música de uma sonata para violino e piano de Beethoven proveniente da sala ao lado." (ADORNO, 2000, p. 147). 
presentes na sociedade para que os educandos e educandas possam reafirmar ou desconstruir sua identidade e reconhecer a legitimidade de outras. (NEIRA, 2007, p. 1).

Nesse sentido, o desafio posto para Educação Física, como destacam Martins e Fensterseifer (2009, p. 1), poderia ser, por meio "da problematização das práticas corporais, potencializar os sujeitos a interferirem nesse universo cultural criando e recriando manifestações adequadas aos seus interesses individuais e coletivos.".

\section{Educação Física na Educação Infantil e a tematização dos esportes}

Neste item ocupamo-nos em descrever, brevemente, algumas possibilidades relacionadas ao trato com o esporte na Educação Infantil. Mesmo que em muitos casos as aulas de Educação Física ocorram em períodos específicos, em sessões delimitadas pelos "ponteiros do relógio" - algo muito criticado no contemporâneo debate sobre a Educação Física da/na Educação Infantil ${ }^{6}$ - esses momentos podem se apresentar como tempos profícuos no sentido de aproximar as crianças do universo das práticas corporais e favorecer o contato com novas e significativas experiências. Nesse sentido, a questão do "tempo da Educação Física na Educação Infantil" precisa ser vista com cuidado, uma vez que, para além das críticas que se colocam em torno da rotina, e da organização dos ambientes educacionais segundo padrões que se destinam à infância em situação escolar - e não àquela de zero a cinco anos - parece importante que, antes, nos perguntemos também sobre $o$ que ocorre, por assim dizer, nos interstícios dos tempos que marcam os momentos de Educação Física.

Sem deixar de considerar essas assertivas apresentamos, a seguir, dois relatos sobre o trato com o esporte na Educação Infantil. O primeiro refere-se a um projeto que tomou o atletismo como tema em aulas de Educação Física da Educação Infantil e o segundo se ocupa de um trabalho realizado com os esportes com bola (futebol, basquetebol, voleibol e handebol) em uma experiência de estágio supervisionado de Educação Física com crianças pequenas.

${ }^{6}$ A Educação Física, assim como os outros momentos da rotina institucional e pedagógica da Educação Infantil, deve, segundo esta perspectiva, respeitar o tempo da criança (de aprender) e não se limitar àquele determinado pelo relógio como, por exemplo, nas aulas dessa disciplina, os três momentos semanais de 35 a 45 minutos, típicos da escolarização (SAYÃO, 2004). 


\section{Da presença do Atletismo na Educação Física da Educação Infantil}

A tematização do esporte na Educação Infantil, e, mais especificamente do atletismo, no caso desse relato, deu-se a partir de algumas indagações da professora no início do ano letivo. Perguntou-se às crianças, com idade entre 3 e 6 anos: O que é Educação Física? O que se pensa e o que se faz na Educação Física? Em unanimidade, embora com diferentes palavras, os pequenos responderam que "na Educação Física a gente brinca"; "a gente faz brincadeiras"; "a gente brinca de areia, brinca com bolinha de sabão, brinca com brinquedo e com joguinho".

Foi pensando naquelas falas das crianças, que levamos para aula uma enorme sacola de tecido que, mais tarde, foi denominada pelas crianças de "saco da Educação Física". No saco, depositamos uma série de materiais que foram inicialmente explorados livremente pelas crianças. Entre os ali presentes havia petecas, raquetes de tênis e tênis de mesa, bolas de voleibol, handebol, basquete e futebol, livros, lápis, revistas da área de Educação Física, canetas, boia, remos, arcos, fitas, colchonete, tacos, dardos, pesos, discos, tabuleiro de xadrez, discos compactos com cantigas de roda e com música erudita, sapatilhas de balé, berimbau, pequenas traves de futebol, cordas, pipas, entre muitos outros.

Às crianças foi explicitado, em linguagem própria, que os materiais se vinculavam a práticas relacionadas aos grandes temas das práticas corporais e que, ao longo do ano, conheceríamos a história desses materiais, os experimentaríamos, conversaríamos sobre eles, conhecendo suas regras, mimetizando os gestos por eles sugeridos, mas também criando outras formas de relação com eles.

Por ocasião da tematização do atletismo, as crianças foram levadas a assistir cenas relacionadas ao esporte, conheceram as diferentes provas da modalidade por meio de imagens, desenhos feitos por elas, recorte e colagem de ilustrações; observaram a escultura do Discobulo (Lançador de discos, esculpuda por Míron em torno de 455 a.C), atentando aos músculos, à posição dos braços e das mãos, à forma de empunhadura; seguraram objetos cujo peso correspondia ao dardo, ao peso, ao disco.

Entre inúmeras outras atividades, as crianças confeccionaram discos com bandejas de papelão, coloriram, escreveram a palavra "disco" ao seu modo, e chegou o dia em que vivenciaram as provas de atletismo na beira da praia, localizada a aproximadamente uma quadra da instituição. A partir de solicitações da professora e, posteriormente, de indicações assinaladas pelas crianças, realizamos: lançamentos de "discos" de vários tamanhos e pesos, a favor e contra o vento; sentados, deitados ou ajoelhados, conforme as crianças iam sugerindo; 
rotações e giros, movimentos continuados e sem pausas, com iniciação lenta e acelerando progressivamente até atingir a ação de lançamento; lançamentos de dardo (galhos de árvore que as crianças encontraram e propuseram que representassem de dardos); saltos em "alturinha" por sobre as ondas: com um só pé, com impulsão, de mãos dadas etc.; corrida de revezamento. Tal proposta envolveu o desafio a cada criança de conduzir um mesmo baldinho contendo água por um determinado trajeto e, ao final, devolvê-lo à professora com algum conteúdo. Saltos junto à água, nas dunas, sobre aglomerados de areia, sobre buracos escavados pelas crianças, sobre discos enfileirados etc. Em várias situações, antes mesmo de solicitar, as crianças já indicavam: "professora, eu tenho uma ideia para o salto em distância" ou "a gente pode lançar assim". Ou ainda: "eu sei como a gente pode fazer de um jeito diferente esse movimento".

Por fim foram-lhes propostas perguntas a respeito dos gestos e movimentos realizados, das dificuldades encontradas, dos saltos, lançamentos e arremessos recriados, das formas, texturas e pesos dos materiais, das variações do vento, dos sentimentos despertados em decorrência das atividades, do prazer ou da dor diante de algum conflito ou da realização de alguma "prova" da modalidade em questão.

Cabe ainda destacar, ao fim desse conciso relato que, ao longo do ano, as crianças foram novamente interrogadas a respeito das aulas de Educação Física: o que é Educação Física? O que se pensa e faz na Educação Física? Entre as respostas, destacamos: "Na Educação Física a gente rebate com a bolinha de muitos jeitos."; "É correr, pular, cabecear, chutar."; "É arremessar, pular, girar."; "Na Educação Física a gente ouve história, diz o que fez na aula, salta do colchão."; "A gente faz ideia diferente de chutar."; "A gente pensa o que tá fazendo e o que a gente fez nas outras aulas"; "A gente faz a regra e depois muda e depois joga de novo"; "A gente vê que tá brigando e vai discutir na reunião"...

\section{Da presença dos Esportes com bola na Educação Física da Educação Infantil}

A tematização dos esportes na experiência de ensino agora relatada (que se deu no contexto da disciplina de Prática de Ensino em Educação Física Escolar II, disciplina da $7^{\mathrm{a}}$ fase do curso de Licenciatura em Educação Física da UFSC) surgiu a partir dos seguintes questionamentos: O que ensinar a crianças tão pequenas (de apenas 5 anos)? Quais conteúdos e conhecimentos da Educa- 
ção Física poderiam ser trabalhados com elas? É possível abordar conteúdos tradicionais, como o esporte, por exemplo? Há espaço para esse conteúdo na Educação Física na Educação Infantil? A partir destas perguntas optou-se pelo esporte como conteúdo das aulas (ministradas num período de dois meses), operando com diferentes modalidades, como o atletismo, a ginástica artística, os esportes aquáticos e com bola, tema que será aqui brevemente apresentado.

A intenção ao se trabalhar com os quatro esportes com bola mais tradicionais no âmbito escolar - handebol, futebol, basquetebol e voleibol - era mostrar às crianças alguns elementos básicos de cada uma das modalidades, como instrumentos, objetivos e a forma peculiar de se jogar em cada caso. Para isso, foram utilizados materiais e espaços que representavam as instalações dessas modalidades, no contexto das quais as crianças puderam conhecer elementos como linhas demarcatórias, traves, tabelas, postes e redes, todos adaptados ao tamanho dos pequenos, como um minicampo e uma miniquadra. Bolas oficiais de cada uma das modalidades também foram utilizadas e puderam ser manuseadas espontaneamente pelas crianças, que sentiram suas dimensões, texturas, pesos e outras especificidades.

Feito isso, passamos a explorar distintas formas de jogar cada esporte, respeitando seus elementos básicos. As crianças separaram-se em grupos e cada um pôde experienciar as singularidades de cada modalidade: chutar a bola de futebol em gol ou arremessar a de handebol, também em gol, utilizando apenas uma das mãos; lançar a bola de basquetebol para o alto, tentando passá-la por dentro da cesta, de cima para baixo (o que causou um pouco mais de dificuldade devido ao tamanho e peso da bola); ou ainda passar a bola de voleibol para o outro lado da rede, por sobre ela, utilizando apenas as mãos. Com o tempo, os grupos iam trocando de estações, passando por todas as modalidades. Além disso, à medida que iam se sentindo mais à vontade, as crianças eram incentivadas a jogarem com os colegas, trocando passes antes de arremessar, lançar, chutar ou transpassar a bola para a quadra oposta.

Vale ressaltar que o intuito deste trabalho não foi ensinar a técnica "mais adequada" de cada modalidade, mas sim, mostrar às crianças que cada esporte tem sua particularidade, tanto no objetivo (fazer gol ou cesta, por exemplo), como nos movimentos que o compõe: que é muito diferente colocar a bola dentro da cesta de cima para baixo do que no sentido inverso, que é mais difícil arremessar uma bola ao gol com apenas uma das mãos do que com as duas, que passar a bola por sobre a rede não é o mesmo que fazê-lo por baixo dela... 


\section{Palavras finais}

Apesar das inúmeras indefinições que se colocam no âmbito da Educação Física na Educação Infantil, parece-nos importante considerar a fatuidade de apresentar às crianças a diversidade de movimentos e materiais historicamente criados e culturalmente desenvolvidos que integram o acervo das práticas corporais, uma vez que, em se tratando de educação (inclusive a infantil), cabe aos professores promover situações pedagógicas intencionais e favorecer experiências formativas que envolvam a expressão das múltiplas linguagens, que incluam formas de se relacionar consigo mesmos, com o outro, com os materiais, com os tempos e os espaços e, sobretudo, que as aproximem das produções culturais. Nessa direção, vale lembrar com Hannah Arendt (2002), que ao professor cabe a responsabilidade de introduzir as crianças em um mundo que lhes é estranho e que lhes deve ser apresentado. Essa responsabilidade assume, na educação, a forma de autoridade. Nas suas palavras:

A qualificação do professor consiste em conhecer o mundo e ser capaz de instruir os outros acerca deste, porém, sua autoridade se assenta na responsabilidade que ele assume por esse mundo. Face a criança, é como se ele fosse um representante de todos os habitantes adultos, apontandolhes detalhes e dizendo à criança: - Isso é o nosso mundo" (ARENDT, 2002, p. 239).

Do contrário, ficam as crianças sujeitas a outras formas de relação com as práticas esportivas, guiadas pelos mecanismos da indústria cultural (ADORNO; HORKHEIMER, 1985) que fazem reinar uma atividade intensa e funcional, determinada por regras arbitrariamente estabelecidas. Para os autores

O estudo concreto do conteúdo ideal da comunicação de massa é tanto mais urgente quando se pensa na inconcebível violência que os seus veículos exercem sobre o espírito dos homens, em conjunto, diga-se de passagem, com o esporte, que passou a integrar, nos últimos tempos, a ideologia, em seu mais amplo sentido. Temos aqui a produção sintética da identificação das massas com as normas e condições que regem anonimamente a indústria cultural ou que a propagam - ou com ambas. Qualquer voz discordante é objeto de censura e o adestramento para o conformismo estende-se até às manifestações psíquicas mais sutis. Nesse jogo, a indústria cultural consegue se apresentar como espírito objetivo, 
na mesma medida em que readquire, em cada vez maior grau, tendências antropológicas em seus clientes. Ao apegar-se a essas tendências, ao corroborá-las e proporciona-lhes uma confirmação, pode simultaneamente eliminar ou até condenar, de forma explícita, tudo o que rejeitar a subordinação. [...] Quanto mais os bens culturais assim elaborados forem proporcionalmente ajustados aos homens, tanto mais estes se convencem de ter encontrado neles o mundo que lhes é próprio. Vemos nas telas da televisão coisas que querem se parecer com as mais habituais e familiares e, entrementes, o contrabando de senhas, como a de que todo estrangeiro é suspeito ou de que o êxito e a carreira são as finalidades supremas da vida, já está dado por aceito e posto em prática, desembaraçadamente, para sempre. Para resumir numa só frase a tendência inata da ideologia da cultura de massa, seria necessário representá-la numa paródia da frase: "converte-te naquilo que és", como duplicação e super-ratificação da situação já existente, o que destruiria toda a perspectiva de transcendência e de crítica. O espírito socialmente atuante e eficaz limita-se, aqui, a pôr, uma vez mais, diante dos olhos dos homens, o que já constitui a condição da sua existência, ao mesmo tempo em que proclama o existente como sua própria norma, e, assim, confirma-os e consolida-os na crença, carente de verdadeira fé, em sua pura existência (ADORNO; HORKHEIMER, 1973, p. 202-203).

O esporte, nos parece, não pode então se limitar a ser perpetrado sem mediação ou simplesmente "desaparecer" como se não compusesse um elemento da cultura, uma vez que, por detrás dele, figurariam todas aquelas premissas que as pedagogias voltadas à infância buscam apagar, tais como a reprodução de regras, o disciplinamento, o rendimento, a técnica e a eficácia motriz, a mecanização e contenção do movimento humano, em favor da imaginação, da interação e da manifestação das múltiplas linguagens infantis. Ao tematizar o esporte na Educação Infantil, pelo contrário, todas aquelas premissas podem ser desconstruídas e contribuir para que, desde cedo, as crianças possam estabelecer uma relação menos danificada com o corpo e com o mundo, por meio da elaboração de formas não convencionais de relação com esse elemento da cultura, passível de ser praticado, experienciado, pensado, recriado e, assim, contribuir para a estruturação de uma nova cultura esportiva no âmbito da Educação Infantil e para além dela.

Entendemos, assim, que a Educação Física na Educação Infantil também pode se ocupar dos grandes temas das práticas corporais, entre eles, o esporte, no sentido de apresentar esse mundo às crianças, oportunizando o diálogo com as variadas formas de expressão corporal presentes na sociedade, tematizando, com elas, novas formas de relação com os objetos culturais que contam a 
história. Do contrário, ficam os pequenos à mercê da celebração dos princípios e normas que regem o universo esportivo, pelas prescrições da indústria do prazer e do entretenimento, ou por uma idealização do lúdico como espaço a ser preservado aprioristicamente, desconsiderando que a ludicidade é também, como nos lembra Bracht (2009), culturalmente moldada.

A valorização da cultura como patrimônio humano e direito, uma vez considerada substância da educação, não significa uma recusa das múltiplas linguagens infantis, nem tampouco do reconhecimento de que as crianças são capazes de expressar-se de maneira complexa em suas brincadeiras, ao tomarem o corpo ou outros objetos como instrumentos de brincar. Ao contrário, a valorização da cultura no espaço institucional pode significar uma ampliação do repertório imaginativo, assim como uma resistência concreta à perversa difusão da cultura, também esportiva, nos esquemas da indústria cultural.

\section{REFERÊNCIAS}

ADORNO, T. Dialética do esclarecimento: fragmentos filosóficos. Rio de Janeiro: Zahar, 1985.

. Educação e emancipação. 2. ed. São Paulo: Paz e Terra, 2000.

; HORKHEIMER, M. Temas básicos da sociologia. São Paulo: Cultrix, 1973.

ARENDT, H. Entre o Passado e o Futuro. São Paulo: Perspectiva, 2002.

ASSIS DE OLIVEIRA, S. Reinventando o esporte: possibilidades da prática pedagógica. 2. ed. Campinas: Autores Associados, 2005.

BASSANI, J. J.; TORRI, D.; VAZ, A. F. Sobre a presença do esporte na escola: paradoxos e ambigüidades. Movimento, Porto Alegre, v. 9, n. 2, p. 89-212, 2003.

BENJAMIN, W. Reflexões: a criança, o brinquedo, a educação. 34. ed. São Paulo: Duas Cidades, 2002.

BRACHT, V. A constituição das teorias pedagógicas da educação física. Cadernos CEDES, 1999, v.19, n. 48, p. 69-88. Disponível em: <http://www.scielo.br/scielo>. Acesso em: 12/10/2009.

. Esporte de Rendimento na Escola. In: STIGGER, M. P.; LOVISOLO, H. (Orgs.) Esporte de Rendimento e Esporte na Escola. Campinas: Autores Associados, 2009. p. 11-27.

BRASIL. Ministério da Educação e do Desporto. Secretaria de Educação Fundamental, Coordenação Geral de Educação Infantil. Referencial Curricular Nacional para Educação Infantil, Conhecimento de Mundo, v. 3, Brasília-DF, 1998. 
. Ministério da Educação. Secretaria de Educação Básica. Política Nacional de Educação Infantil: pelo direito das crianças de zero a seis anos à educação. Brasília: MEC, SEB, 2006.

CAMPOS, M. M. Critérios para um atendimento em creches que respeite os direitos fundamentais das crianças. 6. ed. Brasília: MEC, SEB, 2009.

CAVALARO, A. G.; MULLER, V. R. A educação física na educação infantil: uma realidade almejada. Educar em Revista, Curitiba, n. 34, p. 241-250, 2009.

CESAR, M. R. A. A Invenção da Adolescência no Discurso Pedagógico. São Paulo: UNESP, 2008

KUNZ, E. Transformação Didático-Pedagógica do Esporte. 7. ed. Ijuí: UNIJUÍ, 2009.

MACHADO, T. S.; BRACHT, V.; MORAES, C. E. A.; ALMEIDA, F. Q. de; SILVA, M. A. da. As Práticas de Desinvestimento Pedagógico na Educação Física Escolar. In: CONGRESSO BRASILEIRO DE CIÊNCIAS DO ESPORTE, 16., 2009, Salvador; CONGRESSO INTERNACIONAL DE CIÊNCIAS DO ESPORTE, 3., 2009, Salvador. Anais... Salvador: 2009.

MARTINS, F. D.; FENSTERSEIFER, P. E. Educação Física Escolar como componente curricular: intenções e impasses. Efdeportes, Buenos Aires, Año 13, - n. 128, jan. 2009.

NEIRA, M. G. Educação Física, currículo e cultura: articulando saberes e práticas. In: CONGRESSO NORTE-PARANAENSE DE EDUCAÇÃO FÍSICA ESCOLAR, 3., 2007, Londrina. Anais... Londrina: Centro de Educação Física e Esporte da UEL, 2007.

ROCHA, E. A pesquisa em educação infantil no Brasil: trajetória recente e perspectiva de consolidação de uma pedagogia da educação infantil. Florianópolis: CED/NUP/UFSC, 1999. 290 p. (Teses Nup, 2).

SAYÃO, D. T. O fazer pedagógico do/a professor/a de Educação Física na educação infantil. In: SANTA CATARINA. PMF. SMEI. Caderno de Formação-Divisão de Educação Infantil. Florianópolis, 2004. p. 29-33.

SILVA, T. T. Documentos de identidade: uma introdução às teorias do currículo. Belo Horizonte: Autêntica, 2007.

TABORDA DE OLIVEIRA, M; OLIVEIRA, L.; VAZ, A. F. Sobre corporalidade e escolarização: contribuições para a reorientação das práticas escolares da disciplina de Educação Física. Pensar a Prática, Goiânia, v. 11, p. 100-110, 2008.

TORRI, D.; ALBINO, B. S.; VAZ, A. F. Sacrifícios, sonhos, indústria cultural: retratos da educação do corpo no esporte escolar. Educação e Pesquisa, v. 33, p. 499-512, 2007.

Texto recebido em 31 de dezembro de 2009.

Texto aprovado em 22 de fevereiro de 2010. 